Clinical article. J Neurosurg 2009, 111:371-379.

4. Zanation $\mathbf{A M}$, Carrau $\mathbf{R L}$, Snyderman $\mathbf{C H}$, Germanwala AV, Gardner PA, Prevedello DM, Kassam AB: Nasoseptal flap reconstruction of high flow intraoperative cerebral spinal fluid leaks during endoscopic skull base surgery. Am J Rhinol Allergy 2009, 23:518-521.

5. Fortes FS, Carrau RL, Snyderman $\mathbf{C H}$, Prevedello D, Vescan A, Mintz A, Gardner P, Kassam AB: The posterior pedicle inferior turbinate flap: a new vascularized flap for skull base reconstruction. Laryngoscope 2007, 117:1329-1332.

6. Patel MR, Stadler ME, Snyderman $\mathbf{C H}$, Carrau RL, Kassam AB, Germanwala AV, Gardner $\mathbf{P}$ Zanation AM: How to choose? Endoscopic skull base reconstructive options and limitations. Skull
Base 2010, 20:397-404.

7. Masing H, Gammert C, Jaumann MP: Our concept concerning treatment of septal perforations. Laryngol Rhinol Otol 1980, 59:50-56.

8. Lee DH, Yoon TM, Lee JK, OO YE, Kim IY, Jang WY, Moon KS, Jung S, Lim SC: Clinical utility of the inferior turbinate flaps in the reconstruction of the nasal septum and skull base. J Craniofac Surg 2012, 23:e322-e326.

9. Harvey RJ, Sheahan PO, Schlosser RJ: Inferior turbinate pedicle flap for endoscopic skull base defect repair. Am J Rhinol Allergy 2009, 23:522-526.

10. Gil Z, Margalit N: Anteriorly based inferior turbinate flap for endoscopic skull base reconstruction. Otolaryngol Head Neck Surg 2012, 146:842-847

\title{
ĐĂC ĐIỂM HÌNH THÁI RĂNG NANH VĨNH VIỄN HÀM TRÊN NGẦM QUA PHIM CẮT LỚP VI TÍNH CHÙM TIA HÌNH NÓN
}

\section{TÓM TẮT}

Mục tiêu: Mô tả đặc điểm hình thái răng nanh vĩnh viễn hàm trên ngầm (răng nanh ngầm) qua phim cắt lớp vi tính chùm tia hình nón. Đối tượng và phương pháp nghiên cứu: nghiên cứu mổ tả cắt ngang trên phim CT Conbeam của những bệnh nhân có răng nanh ngầm lấy từ dữ liệu DICOM (Digital Imaging and Communications in Medicine) Kết quả: Tỷ lệ xuất hiện răng nanh ngầm ở nữ $(53.7 \%)$ cao hơn ở nam (46.3\%). Bệnh nhân chỉ có 1 răng nanh vĩnh viễn chiếm đa số (83.33\%). Số răng nanh ngầm đã hoàn thiện chân răng chiếm $63,5 \%$, tỉ lệ răng nanh ngầm không có răng nanh sữa tương ứng là $57.1 \%$. Tỉ lệ răng nanh ngầm có góc với đường giữa trên 45 độ là $55.6 \%$. Răng nanh ngầm nằm về phía tiền đình chiếm $73 \%$. Răng nanh ngầm nghiêng gần chiếm $66.7 \%$. Trường hợp đỉnh răng nanh ngầm ở xa đường nối men-cement nhưng dưới chóp chân răng bên cạnh chiếm $50.8 \%$. Răng nanh ngầm có tình trang bệnh lý hoăc bất thường đi kèm chiếm $63.5 \%$. Kểt luân: Đa số răng nanh ngầm đã hoàn thiện chân răng và phân lớn khồng có răng nanh sữa tướng ứng. Số răng nanh ngầm có trục răng tạo với đường giữa góc trên 45 độ chiếm hơn một nửa các trường hợp nghiên cứu. Về vị trí: theo chiêu trong- ngoài phân lớn răng nanh ngâm nằm về phía tiền đình; theo chiều trên dưới các trường hợp đỉnh răng nanh ngâm ở xa đường nối men - cement nhưng dưới chóp chân răng bên canh chiếm tỉ lệ cao; theo chiều gần-xa phân lớn răng nanh ngầm

\footnotetext{
*Trường Đại học Y Hà Nội

**Bênh viện Răng Hàm Mặt TW Hà Nội

Chịu trách nhiệm chính: Vi Thị Hồng

Email: drvihonghmu@gmail.com

Ngày nhận bài: 21.6.2021

Ngày phản biện khoa học: 16.8.2021

Ngày duyệt bài: 24.8.2021
}

\section{Vi Thị Hồng*, Trần Cao Bính**}

nghiêng gần. Đa số răng nanh ngầm có tình trạng bệnh lý hoặc bất thường đi kèm.

Tư khóa: răng nanh ngầm, phim cắt lớp vi tính chùm tia hình nón.

\section{SUMMARY \\ MORPHOLOGY CHARACTERISTICS OF MAXILLARY IMPACTED CANINES WITH CONE BEAM COMPUTED TOMOGRAPHY}

Aim: The objectives of this study were to describe morphology characteristics of maxillary impacted canines (impacted canine) with Cone Beam Computed Tomography findings. Subjects and methods: We conducted a cross-sectional descriptive study. CT Cone Beam images of patients with impacted canines were taken from DICOM (Digital Imaging and Communications in Medicine). Results: The prevalence of impacted canine in the female group $(53.7 \%)$ was higher than the male group $(46.3 \%)$. Most of subjects had solitary permanent canine $(83.33 \%)$. The percentage of completed root was $63.5 \%$, the percentage of impacted canine with the absence of deciduous canine was $57.1 \%$. There was $55.6 \%$ impacted canine having 45 degree angulation to midline. Impacted canine locating buccally accounted for $73 \%$. Impacted canine locating mesially to the midline accounted for $66.7 \%$. There was $50.8 \%$ impacted canine locating distally from enamel-cement junction but below adjacent tooth's apex. Impacted canine with pathological or abnormal condition accounted for $63.5 \%$. Conclusions: Most of the impacted canines have complete root canals and most have no corresponding deciduous canines. The number of impacted canines with angulation to midline angle more than 45 degrees accounted for more than half of the cases studied. Most of the impacted canines located buccally and had mesially to the midline; the highest point of most impacted canines located distally to the enamel-cement junction 
and below the adjacent tooth's apex; In the mesiodistal direction, most of the canines are mesial inclined. Most impacted canines have pathological or abnormal condition.

Keywords: impacted canine, Cone Beam Computed Tomography.

\section{I. ĐẶT VẤN ĐỀ}

Răng nanh hàm trên là một trong những răng chìa khóa trong sự phát triển của bộ răng vĩnh viễn, vị trí giao nhau của các răng cửa và các răng hàm nhỏ, do đó răng nanh đóng một vai trò quan trọng cả về chức năng và thẩm mỹ. Trong thực hành lâm sàng, các bác sĩ răng hàm mặt thường phải đối mặt với rất nhiều dạng mọc răng bất thường, trong đó có răng ngầm. Răng nanh vĩnh viễn hàm trên mọc ngầm (răng nanh ngầm) là hiện tượng phổ biển chỉ đứng sau răng khôn, chiếm tỉ lệ $0,9 \%-2,2 \% \%$ dân số [1]. Việc điều trị răng nanh ngầm đòi hỏi một kế hoạch phức tạp bao gồm sự kết hợp chặt chẽ giữa phẫu thuật, chỉnh nha và chẩn đoán hình ảnh. Các bác sĩ cần có đầy đủ thông tin về tình trạng răng ngầm, về vị trí, tư thế răng ngầm trong xương hàm và tương quan với các răng và cấu trúc kế cận để để đưa ra quyết định bảo tồn hay lấy bỏ. Như vậy, muốn chẩn đoán chính xác và định hướng điều trị đúng đắn răng nanh ngầm, chẩn đoán hình ảnh đóng vai trò không thể thiếu.

Kỹ thuật chụp cho hình ảnh 3D như CT Cone Beam (Computed Tomography Cone Beam /Chụp cắt lớp với chùm tia hình nón) cho các hình ảnh theo đa chiều trong không gian nên việc đánh giá răng nanh ngầm có thể được thực hiện dễ dàng và chính xác hơn.

Việc đánh giá các đặc điểm của răng nanh ngầm đã được nhiều tác giả trên thế giới quan tâm. Tuy nhiên, ở Việt Nam có ít đề tài được công bố nghiên cứu về răng nanh ngầm, đặc biệt là đề tài nghiên cứu về đặc điểm hình thái răng nanh ngầm trên phim cắt lớp vi tính chùm tia hình nón. Vì vậy, chúng tôi tiến hành nghiên cứu với mục tiêu: Mô tả đặc điểm hình thái răng nanh vĩnh viễn hàm trên ngầm qua phim cắt lớp vi tính chùm tia hinh nón tại bệnh viện Răng Hàm Mặt Trung ương Hà Nội.

\section{II. ĐỐI TƯợNG VÀ PHƯƠNG PHÁP NGHIÊN CỨU}

Đối tượng nghiên cứu: Phim CT Cone Beam của những bệnh nhân có răng nanh ngầm lấy từ dữ liệu DICOM (Digital Imaging and Communications in Medicine), không phân biệt về giới.

Tiêu chuẩn lựa chọn: Phim CT Cone Beam có hình ảnh răng nanh ngầm đã đến tuổi mọc mà vẫn nằm hoàn toàn trong xương hoặc trong niêm mạc, được bao bọc bởi túi mầm răng, độ tuổi lựa chọn bệnh nhân từ 11 tuổi trở lên. Phim CT Cone Beam đạt tiêu chuẩn, hình ảnh chụp rõ nét và đầy đủ hình ảnh răng nanh ngầm, các cấu trúc liên quan và lấy được toàn bộ cung răng trên từ mặt phẳng cắn hàm trên đến hết $1 / 3$ dưới của chiều cao xoang hàm trên.

Tiêu chuẩn loại trừ: Phim CT Cone Beam không đạt tiêu chuẩn, có hình ảnh không rõ nét hoặc lãy thiếu hụt hình ảnh răng nanh cần nghiên cứu. Các trường hợp răng nanh ngầm do dị tật khe hở môi - vòm miệng, các trường hợp rằng nanh ngầm nghi ngờ do yếu tố toàn thân, nội tiết như bệnh Cherubism, hội chứng Down, bệnh lùn tuyến yên, bệnh suy giáp...

Phương pháp nghiên cứu: Thiết kế nghiên cứu mô tả cắt ngang.

Cỡ mẫu và chọn mẫu: chon toàn bô phim CT Cone Beam của 54 bệnh nhân có hình ảnh răng nanh ngầm được chụp tại khoa chẩn đoán hình ảnh và thăm dò chức năng Bệnh viện Răng Hàm Mặt Trung ương Hà Nội từ 8/2020 đến $8 / 2021$.

\section{Các bước tiến hành nghiên cứu:}

Bước 1: lập mẫu nghiên cứu phù hợp với đối tượng và mục đích nghiên cứu.

Bước 2: thu thập phim CT Cone Beam và phân tích, đánh giá các đặc điểm răng nanh ngầm trên phim.

Bước 3: nhập và xử lý số liệu.

Bước 4: tổng hợp và viết báo cáo.

Phương pháp xử lý số liệu: Các số liệu thu thâp được của nghiên cứu được làm sach, mã hóa và nhập bằng phần mềm Excel. Phân tích bằng phần mềm thống kê SPSS 20. Giá trị $p<$ 0,05 được coi là có ý nghĩa thống kê.

Đạo đức trong nghiên cứu: Đây là nghiên cứu quan sát, do đó nguy cơ đối với đối tượng nghiên cứu là không có. Khách quan trong đánh giá, phân loại, trung thực trong xử lý số liệu. Đảm bảo quyền riêng tư của đối tượng nghiên cứu, thông tin thu thập chỉ phục vụ mục đích nghiên cứu và giúp cho công tác dự phòng, điều trị đạt kết quả tốt hơn.

\section{KẾT QUẢ NGHIÊN CỨU}

Bảng 1. Tỷ lệ phân bố răng nanh ngâm theo giới

\begin{tabular}{|c|c|c|c|c|c|}
\hline Giới & & n & $\begin{array}{c}\text { Độ tuối } \\
\text { trung bình } \\
\text { cộng }\end{array}$ & $\begin{array}{c}\text { Độ } \\
\text { lệch } \\
\text { chuẩn }\end{array}$ & \multirow{2}{*}{$\mathbf{p}$} \\
\hline Nam & 46.3 & 25 & 16,64 & 4,45 & \multirow{2}{*}{0,993} \\
\hline Nữ & 53,7 & 29 & 16,48 & 4,73 & \\
\hline
\end{tabular}


Nhận xét: răng nanh ngầm gặp ở nữ (53.7\%) nhiều hơn ở nam (46.3\%), sự khác biệt này không có ý nghĩa thống kê với p> 0.05 .

Bảng 2. Số lượng răng nanh ngầm theo vi trí

\begin{tabular}{|c|c|c|}
\hline $\begin{array}{c}\text { Vị trí răng nanh } \\
\text { ngâm }\end{array}$ & $\begin{array}{c}\text { Số } \\
\text { lượng }\end{array}$ & Tỉ lệ (\%) \\
\hline Bên phải (R13) & 18 & 33,33 \\
\hline Bên trái (R23) & 27 & 50 \\
\hline Cả hai bên & 9 & 16,67 \\
\hline Tống & $\mathbf{5 4}$ & $\mathbf{1 0 0}$ \\
\hline
\end{tabular}

Nhận xét: chủ yếu gặp răng nanh ngầm ở một bển $(83.33 \%)$, chỉ có $16.67 \%$ răng nanh ngầm xuất hiện ở cả hai bên. Sự phân bố răng nanh ngầm bển trái lớn hơn bên phải có nghĩa là răng 23 thường bị mọc ngầm hơn răng 13 , với tỉ lệ răng 23 ngầm lên đến $50 \%$.

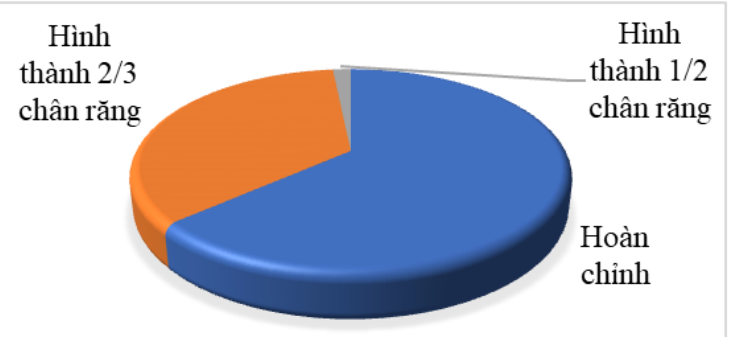

\section{Biểu đồ 1: tình trạng phát triển của răng nanh ngầm.}

Nhận xét: Đa số răng nanh ngầm đã hoàn thiện chân răng $(63,5 \%)$ còn lại là các răng đã hoàn thành $2 / 3$ chân răng $(34,9 \%)$ Chỉ duy nhất 1 trường hợp chân răng mới phát triển hình thành $1 / 2$ chân răng $(1,6 \%)$, không có răng nào mới phát triển $1 / 4$ chân răng.

Bảng 3. Tình trạng răng nanh sữa tương ứng răng nanh ngầm

\begin{tabular}{|c|c|c|}
\hline $\begin{array}{c}\text { Tình trạng răng nanh } \\
\text { sữa tương ứng }\end{array}$ & $\begin{array}{c}\text { Số } \\
\text { lượng }\end{array}$ & $\begin{array}{c}\text { Tỉ lệ } \\
\text { (\%) }\end{array}$ \\
\hline Không có răng nanh sữa & 36 & 57.1 \\
\hline $\begin{array}{c}\text { Không tiêu chân răng } \\
\text { nanh sữa }\end{array}$ & 13 & 20.6 \\
\hline $\begin{array}{c}\text { Tiêu chân răng nanh sữa } \\
\text { tiếp xúc mầm răng }\end{array}$ & 12 & 19.0 \\
\hline $\begin{array}{c}\text { Tiêu chân răng nanh sũa } \\
\text { không tiếp xúc mầm răng }\end{array}$ & 2 & 3.2 \\
\hline Tống & $\mathbf{6 3}$ & $\mathbf{1 0 0 . 0}$ \\
\hline
\end{tabular}

Nhân xét: trong 63 răng nanh ngầm được khảo sát, đa số trường hợp ở thời điểm nghiên cứu không có răng nanh sữa chiếm $57.1 \%$, có răng nanh sữa chiếm $42.9 \%$, các trường hợp không tiêu chân răng sữa và tiêu chân răng sữa tiếp xúc mầm răng chênh lệch không đáng kể (chiếm 20,6 và
19\%), trường hợp tiêu răng sữa không tiếp xúc mầm răng chiếm tỷ lệ thấp $(3,2 \%)$.

Bảng 4: Góc của răng nanh ngâm và đường giữa

\begin{tabular}{|c|c|c|}
\hline Vị trí & Tống & Tỷ lệ \\
\hline Dưới 30 độ & 11 & 17.5 \\
\hline Từ 30 - 45 độ & 17 & 27.0 \\
\hline Trên 45 độ & 35 & 55.6 \\
\hline Tống & $\mathbf{6 3}$ & $\mathbf{1 0 0}$ \\
\hline
\end{tabular}

Nhận xét: Số răng nanh ngầm có góc với đường giữa trên 45 độ chiếm hơn một nửa các trường hợp nghiên cứu (55.6\%). Số răng nanh ngầm có góc với đường giữa dưới 30 độ chiếm $17.5 \%$, trong khi góc với đường giữa trên 30 độ chiếm tỉ lệ cao hơn nhiểu (82.5\%).

Bảng 5: Vị trí theo chiều trong ngoaii của răng nanh ngâm.

\begin{tabular}{|c|c|c|}
\hline Vị trí & Tống & Tỷ lệ \\
\hline Tiền đình & 46 & 73.0 \\
\hline Khấu cái & 12 & 19.0 \\
\hline Chính giữa & 5 & 7.9 \\
\hline Tống & $\mathbf{6 3}$ & $\mathbf{1 0 0}$ \\
\hline
\end{tabular}

Nhân xét: Số lượng răng nanh ngầm trong nhóm nằm về phía tiền đình chiếm tỉ lệ $73 \% \mathrm{caO}$ hơn đáng kể so với nhóm nằm chính giữa hai bản xương $(7.9 \%)$ và nhóm răng hướng về phía khẩu cái $(19 \%)$.

Bảng 6: Vị trí theo chiều gần xa của răng nanh ngầm.

\begin{tabular}{|c|c|c|}
\hline Vị trí & Tống & Tỷ lệ \\
\hline Nghiêng gần & 42 & 66.7 \\
\hline Nghiêng xa & 9 & 14.3 \\
\hline Chính giữa & 12 & 19.0 \\
\hline Tống & $\mathbf{6 3}$ & $\mathbf{1 0 0}$ \\
\hline
\end{tabular}

Nhận xét: Số lượng răng nanh ngầm nghiêng gần chiếm $66.7 \%$, cao hơn đáng kể nhóm răng nghiêng xa (14.3\%) và chính giữa (19\%).

Bảng 7: Vị trí của răng nanh ngâm theo chiều đứng

\begin{tabular}{|c|c|c|}
\hline Vị trí & Tống & Tỷ lệ \\
\hline $\begin{array}{c}\text { Rìa cắn ở mức men- cement } \\
\text { của răng bên cạnh. }\end{array}$ & 23 & 36.5 \\
\hline Rìa cắn ở giữa chân răng bên cạnh & 14 & 22.2 \\
\hline $\begin{array}{c}\text { Rìa cắn ở khoảng 1/3 về phía } \\
\text { cuống chân răng bên cạnh. }\end{array}$ & 18 & 28.6 \\
\hline Rìa cắn trên chóp răng bên cạnh. & 8 & 12.7 \\
\hline Tống & $\mathbf{6 3}$ & $\mathbf{1 0 0 . 0}$ \\
\hline
\end{tabular}

Nhân xét: Số lượng răng nanh ngầm có vị trí ở mức đường ranh giới men-cement của răng bên cạnh chiếm tỉ lệ cao nhất $36.5 \%$, vị trí ở trên chóp răng bên cạnh chiếm tỉ lệ thấp nhất $12.7 \%$. vị trí ở ngang mức giữa chân răng bên cạnh và $1 / 3$ về phía cuống chân răng bên cạnh tương đương nhau với tỉ lệ lần lượt là $22.2 \%$ và $28.6 \%$. 
VIETNAM MEDICAL JOURNAL N01 - SEPTEMBER - 2021

Bảng 8. Biến chứng tiêu chân răng các răng kế cận răng nanh ngầm.

\begin{tabular}{|c|c|c|c|c|c|c|c|}
\hline \multirow{3}{*}{$\begin{array}{l}\text { Loại răng } \\
\text { bị tiêu }\end{array}$} & \multicolumn{6}{|c|}{ Mức độ tiêu chân răng } & \multirow{3}{*}{ Tổng } \\
\hline & \multicolumn{2}{|c|}{ Nhe } & \multicolumn{2}{|c|}{ Trung bình } & \multicolumn{2}{|c|}{ Nặng } & \\
\hline & Số lượng & $\%$ & Số lượng & $\%$ & Số lượng & $\%$ & \\
\hline Răng 1 & 1 & 50 & 0 & 0 & 1 & 50 & 2 \\
\hline Răng 2 & 3 & 50 & 2 & 33.3 & 1 & 16.7 & 6 \\
\hline Răng 4 & 1 & 11.1 & 1 & 11.1 & 7 & 77.8 & 9 \\
\hline Tống số & 5 & 29.4 & 3 & 17.6 & 9 & 53 & 17 \\
\hline
\end{tabular}

Nhận xét: Có 17 răng bị tiêu do răng nanh ngầm. Về vị trí tiêu, răng 4 chiếm tỉ lê nhiều nhất $52.9 \%$. Về mức độ tiêu thì chủ yếu gặp tiêu chân răng ở mức độ nặng (53\%).

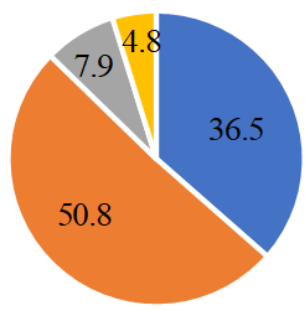

" Không có vấn đề

" Có 1 bệnh lý, bất thường liên quan răng nanh ngầm

" Có 2 bệnh lý, bất thường liên quan răng nanhngầm

Có 3 bệnh lý, bất thường liên quan răng nanhngầm

Biểu đồ 2. Các vấn đề liên quan đến răng nanh ngâm.

Nhận xét: Có $36,5 \%$ số răng nanh ngầm không có tình tình trạng bất thường hoặc kèm bệnh lý. Còn lại $63,5 \%$ là có các vấn đề liên quan răng nanh ngầm. Trong đó, tỷ lệ các răng nanh ngầm có kèm một bệnh lý hoặc bất thường chiếm $50,8 \%$, tỷ lệ rắng kèm 2 bệnh lý và bất thường là $7,9 \%$, cuối cùng là tỷ lệ kèm 3 bệnh lý hoặc bất thường thường là 4,8\%.

\section{BÀN LUẬN}

Kết quả nghiên cứu của chúng tôi cho thây tỉ lệ răng nanh ngầm ở nữ cao hơn ở nam với tỉ lệ $53.7 \%$. Số chênh lệch này là nhỏ và không có ý nghĩa thống kê, tuy nhiên kết quả này cũng phù hợp với một số nghiên cứu trên thế giới cũng như trong nước: nghiên cứu của Silva Santos LM. và cộng sự năm 2014[2] tỉ lệ gặp răng nañh ngầm ở nứ là $70 \%$; và nghiên cứu của Nguyễn Phú Thắng năm 2012 tỉ lệ này là $62.1 \%$ [3].

Bệnh nhân chỉ có một răng nanh ngâm chiếm đa số (83.33\%). Sự phân bố răng nanh ngầm bên trái lớn hơn bển phải có nghĩa là răng 23 thường bị mọc ngầm hơn răng 13 , với tỉ lệ răng 23 ngầm lên đến $50 \%$; điều này cũng phù hợp với kết quả nghiên cứu của Võ Trương Như Ngọc năm 2014 tỉ lệ răng 23 ngầm là 58.06\%; trong

khi đó nghiên cứu của Agnini M năm 2007 lại cho kết quả ngược lại: răng nanh ngầm bên phải gặp nhiêu hơn bền trái [4].

Đa số răng nanh ngầm trong nghiên cứu đã hoàn thiện chân răng (chiếm $63,5 \%$ ) còn lại là các răng đã hoàn thành $2 / 3$ chân răng (chiếm $34,9 \%$ ) Chỉ duy nhất 1 trường hợp chân răng mới phát triển hình thành $1 / 2$ chân răng (chiếm $1,6 \%)$, không có răng nào mới phát triên $1 / 4$ chân răng. Kết quả này khá tương đồng với nghiên cứu của Võ Trương Như Ngọc (2014) [5] với các tỉ lệ tương ứng là $86.5 \%, 13.5 \%$, không gặp răng nào trong nhóm phát triển $1 / 4$ đến $1 / 2$ chẩn răng.

Đa số trường hợp ở thời điểm nghiên cứu không có răng nanh sữa chiếm $57.1 \%$. Trong số các trường hợp có răng nanh sữa, tỉ lệ không tiêu chân răng nanh sữa là $48.1 \%$, tiểu chân răng nanh sữa tiếp xúc mầm răng là $44.4 \%$ và tiêu chân răng nanh sữa không tiếp xúc mầm răng là $7.4 \%$. Kết quả này phù hợp với nghiên cứu của Alquerbal $A$. và cộng sự (2011) với các tỉ lệ tương ứng là $39.2 \%, 41.2 \%$ và $19.6 \%$ [6].

Số răng nanh ngầm có góc với đường giữa trên 45 độ chiếm hơn môt nửa các trường hợp nghiên cứu (55.6\%). Số răng nanh ngầm có góc với đường giữa dưới 30 độ chiếm $17.5 \%$, trong khi góc với đường giữa trên 30 độ chiếm tî lệ cao hơn nhiểu $(82.5 \%)$. Kết quả này có sự tương đồng với kết quả trong nghiên cứu của Mohammad Hosein cà cộng sự (2009) với tỉ lệ tương ứng là $40 \%$ và $60 \%$ [7].

Tí lệ nhóm răng nanh ngầm ở phía tiền đình so với nhóm răng ngầm nằm ở phía khẩu cái gần bằng $3: 1$. Tỉ lệ này phù hợp với các kết quả nghiên cứu về răng nanh ngầm ở người Châu Á, tỉ lệ răng nanh ngầm ở phía tiền đình luôn cao hơn phía vòm miệng, như trong nghiên cứ của Bin Yan và cộng sự ở người Hàn Quốc (2012) [8] cho kết quả tỉ lệ rắng nanh ngầm phía tiền đình/ khẩu cái là $3: 1$, trong nghiên cứu ở Việt Nam của Nguyễn Phú Thắng(2012) và Võ Trương Như Ngọc (2014) tỉ lệ này là gần 2:1.

Số lượng răng nanh ngầm có vị trí ở mức đường ranh giới men-cement của răng bên cạnh chiếm tỉ lệ cao nhất $36.5 \%$, vị trí ở trên chóp 
răng bên cạnh chiếm tỉ lệ thấp nhất $12.7 \%$. Kết quả nghiên cứu của chúng tôi có sự tương đồng với nghiên cứu của Võ Trương Như Ngọc với các tỉ lệ tương ứng là $35.1 \%$ và $16.2 \%$ [5].

Có $27 \%$ răng nanh ngầm gây tiêu chân răng lân cận, tỉ lệ này thấp hơn so với nghiên cứu của Bin Yan và cộng sự (2015) [8] tỉ lệ này là 49.5\%.

\section{KẾT LUÂ̂N}

Tỷ lệ xuất hiện răng nanh vĩnh viễn hàm trên ngầm ngầm ở nữ cao hơn ở nam.

Bệnh nhân chỉ có 1 răng nanh vĩnh viễn hàm trên ngầm chiếm đa số (83.33\%).

Đa số răng nanh hàm trên ngầm trong nghiên cứu đã hoàn thiện chân răng (chiếm $63,5 \%$ ) và phần lớn không có răng nanh sữa tương ứng (57.1\%).

Số răng nanh vĩnh viễn hàm trên ngầm có góc với đường giữa trên 45 độ chiếm hơn một nửa các trường hợp nghiên cứu (55.6\%).

Về vị trí: theo chiều trong- ngoài thì phần lớn răng nanh vĩnh viễn hàm trên ngầm ở phía tiền đình (73\%); theo chiều trên dưới thì gặp nhiều ở các trường hợp đỉnh răng nanh vĩnh viễn hàm trên ngầm ở xa đường CEJ nhưng dưới chóp chân răng bên cạnh (50.8\%); theo chiều gần-xa thì răng nanh vĩnh viến hàm trên ngầm chủ yếu nghiêng gần (66.7\%).

Đa số răng nanh vĩnh viễn hàm trên ngầm trong nghiên cứu có tình trạng bệnh lý hoặc bất thường đi kèm ( 63.5\%).
TÀI LIỆ THAM KHẢO

1. Alqerban A., Storms A.-S., Voet M. và cộng sự. (2016). Early prediction of maxillary canine impaction: number doubts: Author response. Dentomaxillofac Radiol, 45(6), 20160263.

2. da Silva Santos L.M., Bastos L.C., OliveiraSantos C. và cộng sự. (2014). Cone-beam computed tomography findings of impacted upper canineș. Imaging Sci Dent, 44(4), 287-292.

3. Nguyễn Phú Thẳng (2012). Nghiên cứu phẫu thuật hỗ trợ quá trình chỉnh nha các răng vĩnh viễn mọc ngầm vừng trước. Luận án tiến dĩ chuyên ngành Răng hàm mặt, Đại học Y Hà Nội. .

4. Agnini M. (2007). The panoramic $X$-ray as a detector for preventing maxillary canine impaction. Int J Orthod Milwaukee, 18(4), 15-23.

5. Võ Trương Như Ngọc, Lương Thị Minh Hằng. (2014). Một số đăc điểm của răng nanh ngầm hàm trên trên phim CT Conebeam. Tạp chí $Y$ học Việt Nam, 424, 124 - 129. .

6. Alqerban A., Jacobs R., Fieuws S. và cộng sự. (2011). Comparison of two cone beam computed tomographic systems versus panoramic imaging for localization of impacted maxillary canines and detection of root resorption. Eur J Orthod, 33(1), 93-102.

7. Motamedi M.H.K., Tabatabaie F.A., Navi F. và cộng sự. (2009). Assessment of radiographic factors affecting surgical exposure and orthodontic alignment of impacted canines of the palate: A 15year retrospective study. Oral Surgery, Oral Medicine, Oral Pathology, Oral Radiology, and Endodontology, 107(6), 772-775.

8. Yan B., Sun $Z$., Fields H. và cộng sự. (2015). [Maxillary canine impaction increases root resorption risk of adjacent teeth: A problem of physical proximity]. Orthod Fr, 86(2), 169-179.

\section{ĐẶC ĐIỂM LÂM SÀNG, CÂ̂N LÂM SÀNG VIÊM PHỔI NHIỄM CHLAMYDIA PNEUMONIAE VÀ MYCOPLASMA PNEUMONIAE Ở TRẺ EM TẠI BÊ̂NH VIÊ̂N NHI TRUNG ƯO'NG}

\section{TÓM TẮT}

Nghiên cứu mô tả cắt ngang đặc điểm lâm sàng, cânn lầm sà̀ng của 109 trẻ tữ 1 đến 15 tuổi mắc viêm phổi nhiểm Chlamydia pneumoniae (CP) hoặc Mycoplasma pneumoniae (MP) tại bệnh viện Nhi Trung ương từ 8/2020 đến 7/2021. Viêm phổi nhiếm $\mathrm{CP}$ và $\mathrm{MP}$ gặp chủ yếu ở nhóm trẻ từ 1 đến 5 tuổi $(57,1 \%$ và $62,7 \%)$. Biểu hiện lâm sàng viêm phổi

\footnotetext{
${ }^{1}$ Bệnh viện Nhi Trung ương

${ }^{2}$ Trường Đại học Y Hà Nội

Chịu trách nhiệm chính: Hà Thị Thanh Vân

Email: bs.hathanhvan@gmail.com

Ngày nhận bài: 22.6.2021

Ngày phản biện khoa học: 17.8.2021

Ngày duyệt bài: 24.8.2021
}

Hà Thị Thanh Vân ${ }^{1}$, Nguyễn Thị Yến ${ }^{2}$ nhiễm CP và MP tương tự nhau, chủ yếu là ho $(100 \%$; $97,1 \%)$, sốt $(85,7 \%$; $96,1 \%)$, khò khè $(57,1 \%$; $25,6 \%)$ và nghe phổi có ran $(57,1 \% ; 57,8 \%)$. Viêm phổi nhiếm $\mathrm{CP}$ thường sốt nhẹ $(85,7 \%)$ và không ghi nhâan trường hợp nào có suy hô hấp, còn viêm phổi nhiễm MP thường sốt cao $(66,7 \%)$ và có thể diễn biến suy hô hấp $(21,6 \%)$. X-quang hay gặp nhất là mờ 2 rốn phổi và đông đặc thùy phổi. Tràn dịch màng phổi thấy ở nhóm viêm phổi nhiếm MP (4,9\%). Xét nghiệm máu cho thây hầu hết các trường hợp có bạch câuu tăng nhẹ và tăng CRP.

Tư khóa: viêm phổi, trẻ em, Chlamydia pneumonia, Mycoplasma pneumonia.

\section{SUMMARY \\ THE CLINICAL AND SUBCLINICAL CHARACTERISTICS OF MYCOPLASMA}

